\title{
أسباب سوء استذام وسائل التواصل الاجتماعي (تويتر أنموذجاً)
}

\author{
ماجد عبد الفتاح محمد بخاري \\ كلية التربية - قسم علم النفس - إحصاء وبحوث \\ M-BOUKHARI@hotmail.com
}

الملخص:

هدفت الدراسة إلى التعرف على أسباب سوء استخدام وسائل التواصل الاجتماعي من خلال تويتر كأنموذج حديث لوسائل

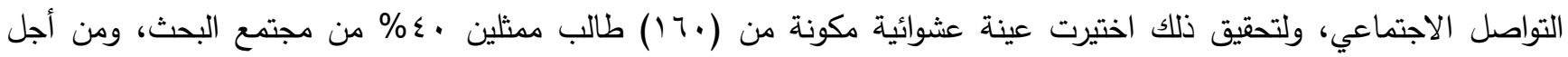
الإجابة عن أسئلة الدراسة تم تصميم استبيان لمعرفة أسباب سوء استخدام وسائل التواصل الاجتماعي (تويتر Twitter أنموذجًا) ومعوقات الاستخدام الأمثل، ومقترحات الحد من سوء استخدام تلك الوسيلة، ثم استخدم الباحث المعالجات الإحصائية بعد تحليل الاستمارات عبر البرنامج الإحصائي SPS v.23 ، وأسفرت نتائج التحليل الإحصائي عن: معرفة أهم أسباب سوء استخدام وسائل

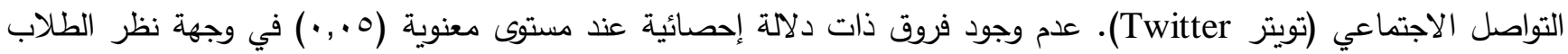

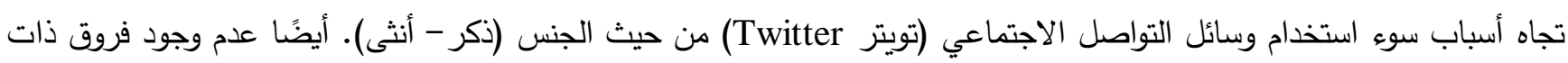
دلالة إحصائية عند مستوى معنوية (0., •) في وجهة نظر الطلاب تجاه أسباب سوء استخدام وسائل التواصل الاجتماعي (تويتر (Twitter من حيث العمر. معرفة أهم معوقات الاستخدام الأمثل لوسائل التواصل الاجتماعي (تويتر (Twitter). معرفة أهم

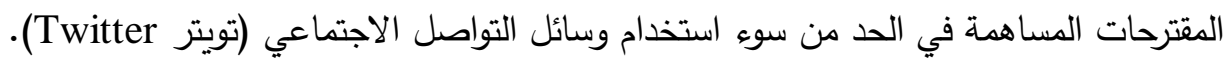

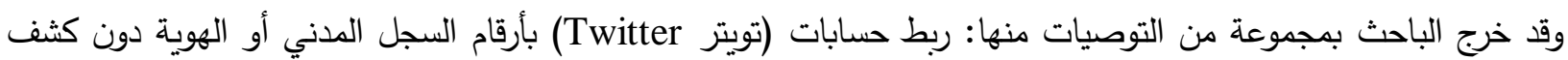
المعلومات لغير العاملين في المنظومة الرقابية، وضرورة تفعيل (تويتر Twitter) عبر مكاتب التربية والتعليم والمدارس والمعاهد والجامعات وجميع المؤسسات الإدارية، وأهمية إنشاء لجان إلكترونية متخصصة دينية وعلمية ونفسية وقانونية للتوعية في كافة

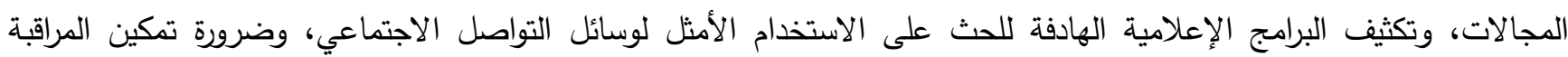
الإكترونية للجهات المعنية بالصلاحيات لمعاقبة المخالفين للأنظمة ومثيري الفتن.

الكلمات المفتاحية: وسائل التواصل الاجتماعي، (تويتر Twitter)، سوء استخدام وسائل التواصل الاجتماعي. (a) (1)

يُعد مفهوم المساندة الاجتماعية مفهومًا حديثًا نسبيًا، حيث تتاوله علماء النفس والاجتماع في إطار بحثهم للعلاقات النفسية

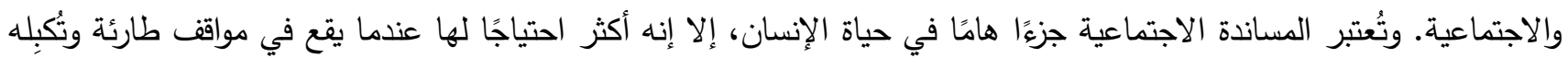
الضغوط، حيث إن البيئة الاجتماعية هي مجال لتوفير المساندة نظراً لكونها تشمل مجموعة من المصادر التي يمكن للفرد أن يلجأ إليها مثل الأسرة والأصدقاء والأقارب والجيران وغيرهم من أفراد المجتمع. وتختلف المساندة الاجتماعية باختلاف المرحلة العمرية 
التي يمر بها الفرد، كما تختلف باختلاف المراحل الزمنية التي يعيش فيها الفرد من حيث الوسائل والتقنيات. ولعل من أهم وسائل

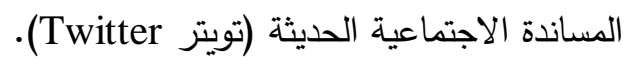
وتُعتبر المساندة الاجتماعية من المتغيرات التي اختلف الباحثون حول تعريفها وفقًا لتوجهاتهم النظرية، وقد تتاول علماء النفس النس

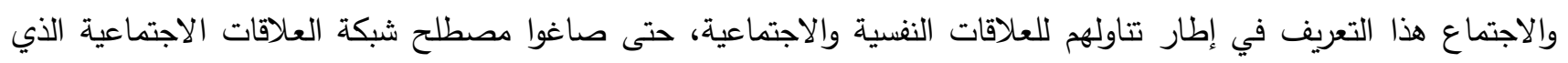
يُعتبر البداية الحقيقية لظهور مصطلح المساندة الاجتماعية والذي يُطلق عليه البعض مسمى الإمكانيات الاجتماعية. (الثناوي، ويعرّف (Kabland, 1996) المساندة الاجتماعية بأنها "النظام الذي يتضمن مجموعة من الروابط والتفاعلات الاجتماعية مع الآخرين تتسم بأنها طويلة المدى، ويمكن الاعتماد عليها والثقة بها عند إحساس الفرد بالحاجة إليها لتمدُه بالسند العاطفي".

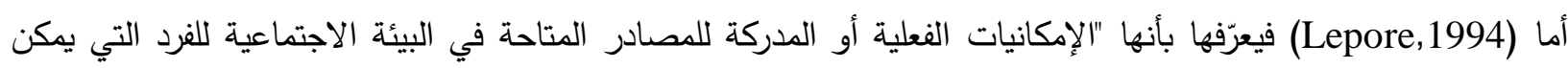
استخدامها للمساعدة الاجتماعية في أوقات الضيق، ويتزود الفرد بالمساندة الاجتماعية من خلال شبكة علاقاته الاجتماعية التي الإني تضم كل الأشخاص الذين لهم اتصال اجتماعي منتظم بشكل أو بآخر مع الفرد".

وسائل التواصل الاجتماعي: إن لوسائل التواصل الاجتماعي أهمية كبيرة، وقد شهدت النتشارًا واسعًا خلاع السنوات الأخيرة، وتعددت بأنواع منها: تويتر ، وفيسبوك، ويوتيوب، وسناب شات، وغيرها.

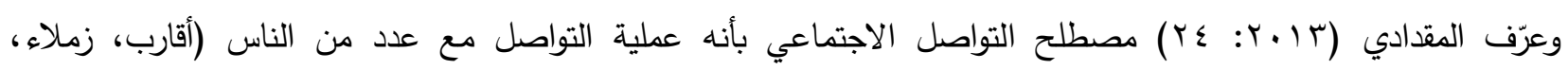

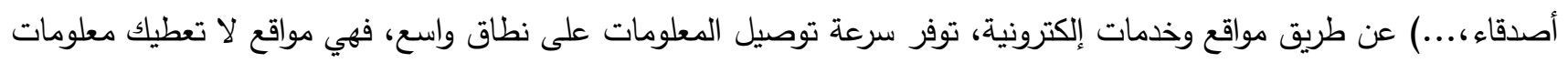

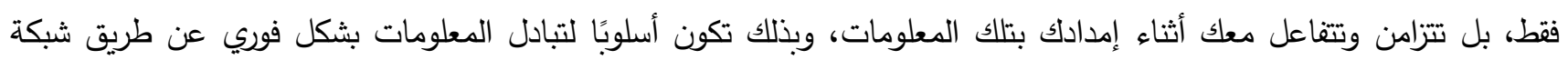
الإنترنت. • (Twitter) • ذكر (المحارب، 1) 1 (ب) أن تويتر (Twitter) هو إحدى شبكات التواصل الاجتماعي التي انتشرت في السنوات الأخيرة، وأخذ تويتر (Twitter) اسمه من مصطلح "تويت" والذي يعني "التغريد"، وهو خدمة مصغرة تسمح للمغردين إرسال رسائل نصية قصيرة لا تتعدى • ـا حرف للرسالة الواحدة، ويمكن لمن لديه حساب في تويتر (Twitter) أن يتبادل مع أصدقائه تلك التغريدات من فن خلال ظهورها على صفحاتهم الشخصية، أو في حالة دخولهم على صفحة المستخدم صاحب الرسالة. وللتدوين عبر تويتر (Twitter)

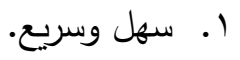

$$
\begin{aligned}
& \text { r. . مجاني بعكس الرسائل العادية عبر الجوال. }
\end{aligned}
$$

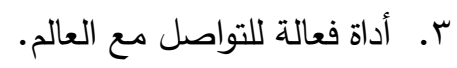

$$
\begin{aligned}
& \text { دوافع استخدام وسائل التواصل الاجتماعي: }
\end{aligned}
$$

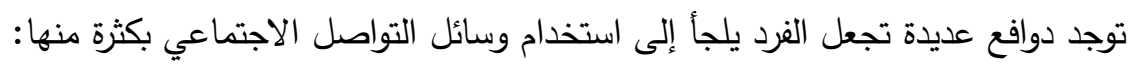

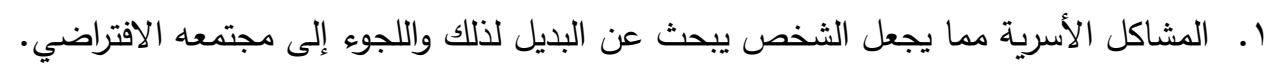
r. الفراغ وسوء استغلال الفرد لوقته مما يدفعه إلى التواصل مع غيره عبر وسائل التواصل الاجتماعي المتعددة. r. البطالة وعدم توفر فرص اللعمل تدفعه إلى التوجه إلى العالم الافتراضي.

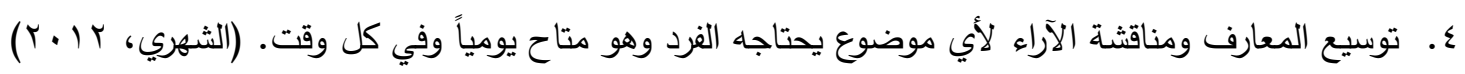
الآثار الإيجابية والسلبية لوسائل التواصل الاجتماعي: تؤثر وسائل التواصل الاجتماعي على أفراد المجتمع بصورة كبيرة تأثيرات إيجابية وسلبية، أما التأثيرات الإيجابية منها: 
ا. ـ تُساعد وسائل التواصل الاجتماعي على التعرف على ثقافات الشعوب. r. ت تميز ببساطة اللغة حيث أن جميع الطبقات الاجتماعية يمكنها استخدامها. r. أنها توفر الوقت والجهد والمال. ع. تُمكن المستخدم من الاطلاع بشكل واسع بما يدور في العالم. ه. تُمكن المبتدئين في مجال التجارة بتسويق منتجاتهم.

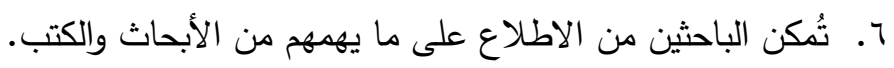

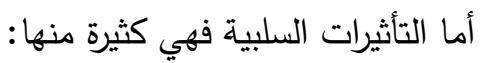
ا ـ إحداث زعزعة وخطورة على التماسك الأسري وفقدان التواصل. r. أن وسائل التواصل الاجتماعي تهدم القيم.

r. المبالغة في الكثف عن أسرار الحياة الثخصية والأسرية والاجتماعية. ع. الوقوع في الثك والريبة والوصول إلى الطلاق والثقاق والنزاع بين الأزواج.

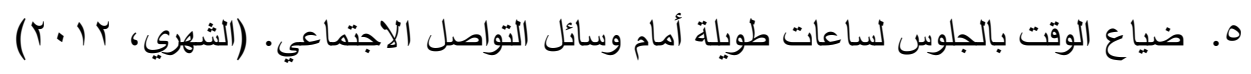
أهمية الدراسةة:

تبرز أهمية هذه الدراسة من خلال موضوعها التواصل الاجتماعي وماله من دور قوي وملموس في التأثير على المجتمعات

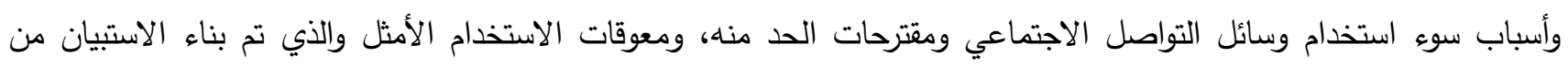
أجله. ويمكن إيجاز أهمية الدراسة فيما يلي: ا. عدم وجود دراسات مماثلة تتطرق لأسباب سوء استخدام وسائل التواصل الاجتماعي (تويتر Twitter أنموذجًا)، في حين تواترت الدراسات حول تأثير وسائل التواصل الاجتماعي.

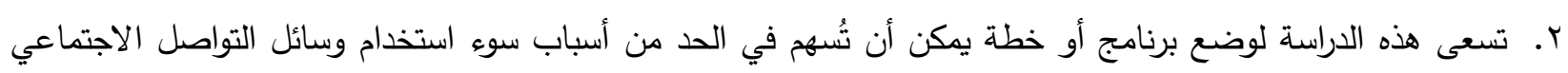
(تويتر Twitter) لتصل به إلى الاستخدام الأمثل المؤمل منه.

\section{مشكلة الاراسة:}

من خلال الاطلاع والبحث تبين لاى الباحث تعدد وتتوع أسباب سوء استخدام وسائل التواصل الاجتماعي (تويتر Twitter أنموذجًا)، وكان من أبرز هذه الأسباب عدم الوعي الاجتماعي بقيمة وسائل المساندة الاجتماعية متمثلة في وسائل التواصل لإنل

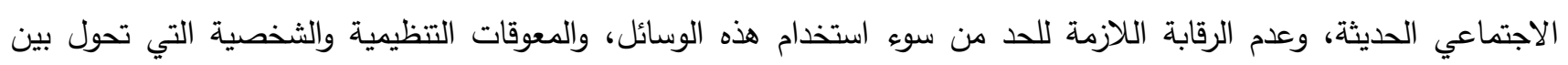
الاستخدام الأمثل لوسائل التواصل الاجتماعي الحديثة.

أهداف الاراسة:

ا. التعرف على أسباب سوء استخدام وسائل التواصل الاجتماعي (تويتر Twitter).

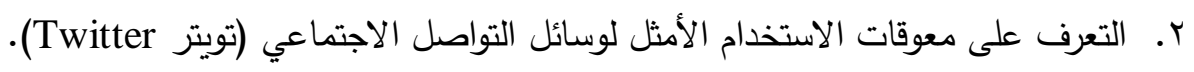
r. الوصول إلى مقترحات وتوصيات يُمكنها المساهمة في الحد من سوء استخدام وسائل التواصل الإتل الاجتماعي (تويتر

(Twitter

أسئلة الارارسة:

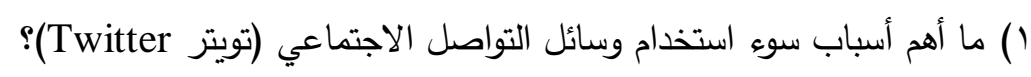

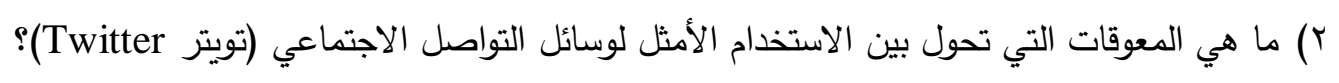


r) ما هي أهم مقترحات وتوصيات المساهمة في الحد من سوء استخدام وسائل التواصل الاجتماعي (تويتر Twitter)؟ فرضيات الاراسة: ا. الفرض الصفري الأول: لا توجد فروق ذات دلالة إحصائية عند مستوى معنوية (0., ·) في وجهة نظر الطلاب تجاه

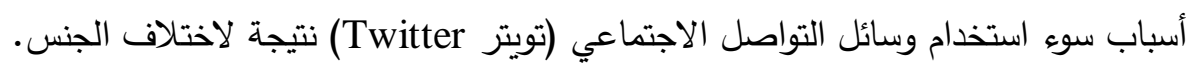
r. الفرض الصفري الثاني: لا توجد فروق ذات دلالة إحصائية عند مستوى معنوية (0., •) في وجهة نظر الطلاب تجاه أسباب سوء استخدام وسائل التواصل الاجتماعي (تويتر Twitter) نتيجة لاختلاف العمر .

\section{إجراءات الدراسة:}

منهج الاراسة:

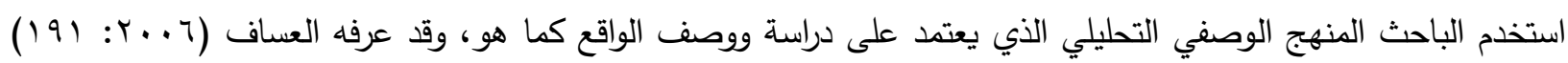
بأنه "يصف الظاهرة المدروسة وصفاً كميًا وكيفيًا من خلال جمع المعلومات وتصنيفها، ومن ثم تحليلها وكثف العلاقة بين أبعادها

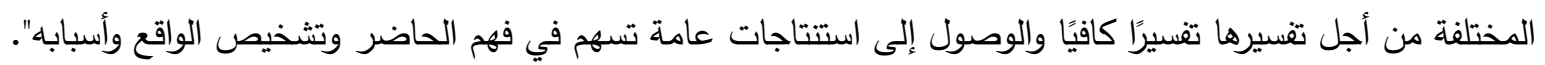
مجتمع الاراسة: يتكون مجتمع الدراسة من ( . .ـ أ) طالب من مستخدمي وسائل التواصل الاجتماعي (تويتر Twitter) بكلية التربية بجامعة أم

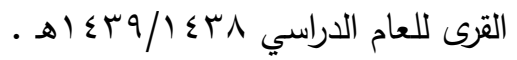
عينة الدراسة: تم اختيار أفراد عينة الدراسة باستخدام الطريقة العشوائية البسيطة والتي تعني "أن الفرصة متساوية ودرجة الاحتمال واحدة لأي

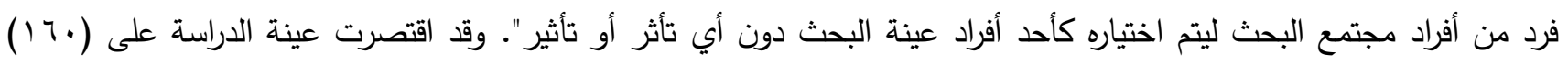

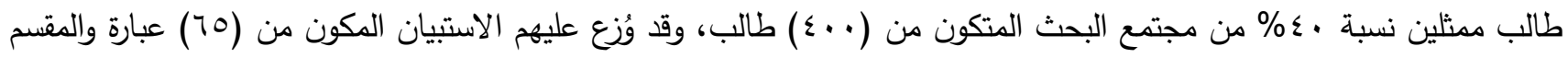

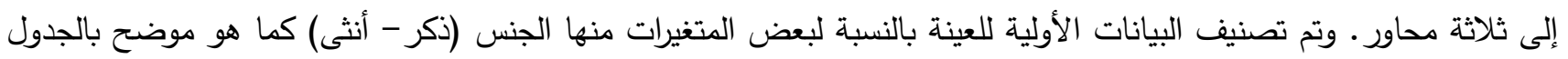

جدول ( ) يوضح النسب المئوية وإلتكرارات لمفردات العينة حسب الجنس

\begin{tabular}{|c|c|c|c|}
\hline النسبة المئوية & التكرارات & الجنس & م \\
\hline$\%$ \% , & 0. & ذكر & 1 \\
\hline$\% \nmid \lambda, \vee$ & 11. & أنثى & $r$ \\
\hline$\% 1 \ldots$ & 17. & & \\
\hline
\end{tabular}

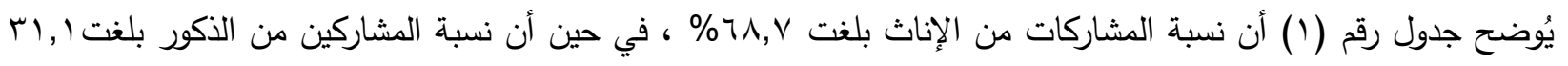
\% من إجمالي أفراد عينة الدراسة. جدول (ץ): يوضح النسب المئوية والتكرارات لمفردات العينة حسب للعمر

\begin{tabular}{|c|c|c|c|}
\hline النسبة المئوية & التكرالات & 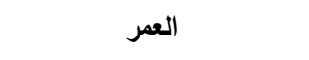 & 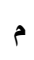 \\
\hline$V r, 0$ & 117 & من 1 1 إلى أقل من ه ץ عام & 1 \\
\hline$r \cdot, T$ & זr & 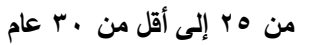 & r \\
\hline 7,9 & 11 & أكبر من · · عام & $r$ \\
\hline$\% 1 \ldots$ & 17. & 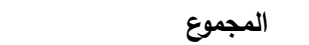 & \\
\hline
\end{tabular}




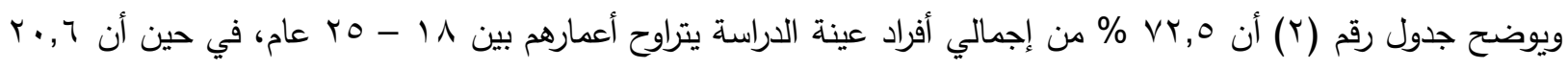

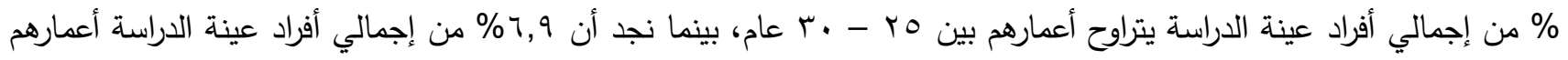
أكبر من • أب عام. أداة الدراسة: لجمع المعلومات المتعلقة بهذه الدراسة والإجابة عن أسئلتها، وتحقيق أهدافها، قام الباحث بتصميم استبيان مكون من ثلاثة محاور، وهي: • التعرف على واقع التواصل الاجتماعي من خلال أسباب سوء استخدام وسائل التواصل الاجتماعي (تويتر Twitter).

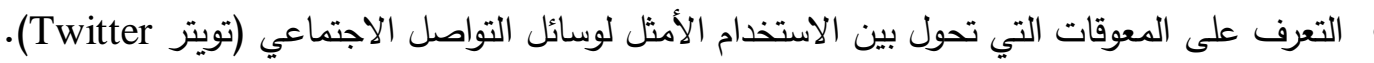
• التعرف على مقترحات وتوصيات يُمكنها المساهمة في الحد من سوء استخدام وسائل التواصل الاجتماعي (تويتر (Twitter). وقد تكونت الاستبانة من:

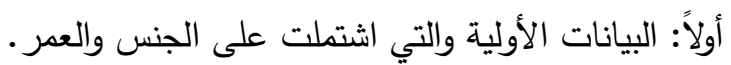
ثانياً: المحاور التي تكونت من (70) عبارة موزعة على ثلاثة محاور رئيسية: المحور الأول منها مقسم إلى سبعة عناصر ، والمحور

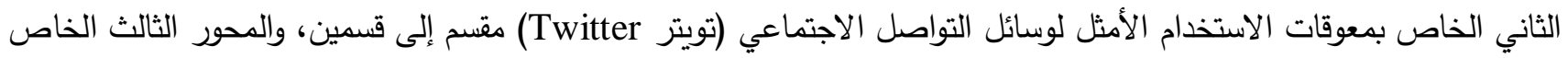
بالمقترحات ينقسم إلى قسم واحد. وقد استخدم الباحث مقياس ليكرت الرباعي (موافق بشدة، موافق، غير موافق، غير موافق بشدة) حيث يعبر الرقم (ع) عن (موافق بشدة) ويعبر الرقم (1) عن (غير موافق بشدة). صدق أداة الاراسة:

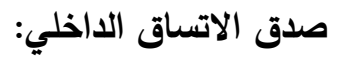
تم حساب صدق الاتساق الداخلي عن طريق إيجاد قيمة معامل الارتباط بيرسون بين درجة كل سبب من أسباب سوء استخدام وسائل التواصل الاجتماعي (تويتر Twitter) والدرجة الكلية لدحور واقع التواصل الاجتماعي كما هو موضح في الجدول التالي: جدول(ץ): قيم معاملات الارتباط بين درجة كل سبب من أسباب سوء استخدام وسائل التواصل الاجتماعي والدرجة الكلية للمحور

\begin{tabular}{|c|c|c|}
\hline قيمة معامل الارتباط & السبب & م \\
\hline$* *, 00 r$ & ضعف التوثيق & 1 \\
\hline$* *, V \cdot T$ & الكنب والإشاعات & $r$ \\
\hline$* *, V Y I$ & التشبث بالرأي & $r$ \\
\hline$* *, \vee \backslash \leq$ & إثارة المشكلات & $\varepsilon$ \\
\hline$* *, 071$ & المخاطرة في الطرح & 0 \\
\hline$* *, T \vee \leqslant$ & عدم القدرة على التحليل & 7 \\
\hline$* *, V \cdot T$ & الخروج عن المألوف & $v$ \\
\hline
\end{tabular}

ويتضح من خلال جدول رقم (r) أن دلالة قيم معاملات الارتباط دالة إحصائياً حيث تراوحت بين هor, . كحد أدنى وبين

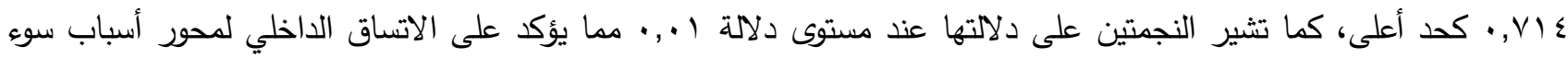

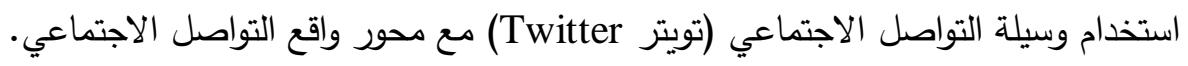
ثبات أداة الدراسة: قام الباحث بحساب معامل ثبات الاستبانة وذلك باستخدام ألفا كرونباخ للتأكد من ثبات أداة الدراسة وذلك على العينة

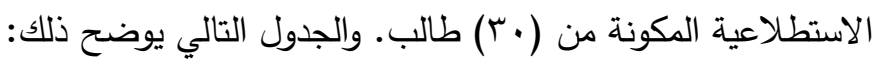


جدول(؛) ): يوضح ثبات أداة الداسة باستخدام معامل ألفا كرونباخ

\begin{tabular}{|c|c|c|}
\hline (ألفا كرونباخ) & 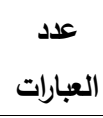 & المحاور \\
\hline$\cdot, \wedge \leq \wedge$ & ro & 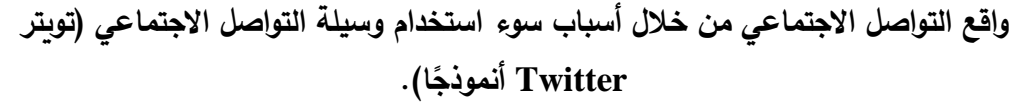 \\
\hline$\cdot, \mathrm{V} \backslash \leq$ & 11 & معوقات الاستخدام الأمثل لوسائل التواصل الاجتماعي (تويتر Twitter أنموذجًا). \\
\hline$\cdot, \vee \vee q$ & Ir & مقترحات وتوصيات يُمكنها المساهمة في الدد من سوء استخدام وسائل التواصل الاجتماعي \\
\hline$\cdot, \Lambda ו r$ & 70 & الثبات الكلي لجميع محاور الاستبيان \\
\hline
\end{tabular}

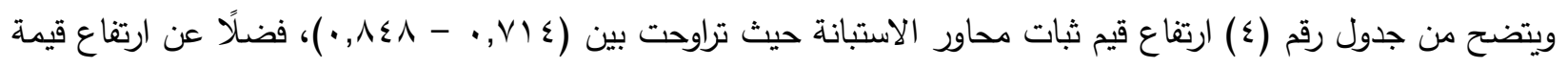

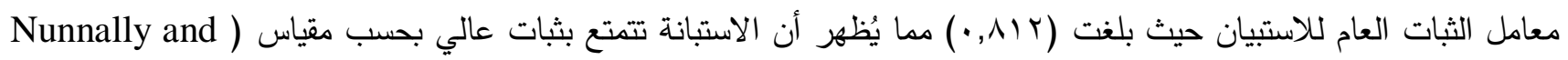
(Bernstein, 1994 وبعد أن أعدّ الباحث أداة الدراسة في صورتها الأولية وعرضها على المحكمين من المختصين، ومن ثم اعتماد صورتها النهائية، قام الباحث بتوزيع الاستبيان على أفراد عينة الدراسة. وبعد جمع الاستبيان واستبعاد غير الصالح منها واستكمال عدد وصدئ

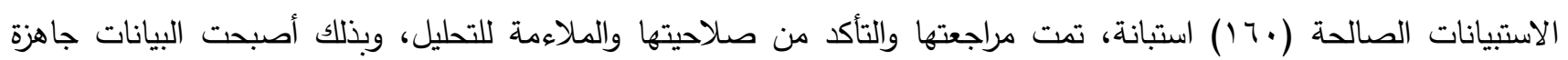
للمعالجة الإحصائية ومن ثم الحصول على نتائج الدراسة. المعالجة الإحصائية المستخدمة: في ضوء أهداف الدراسة وتساؤلاتها قام الباحث باستخدام برنامج الحزم الإحصائية للعلوم الاجتماعية (SPSS v.23) للحصول على النتائج، باستخدام الأساليب الإحصائية التالية:

$$
\begin{aligned}
& \text { • • التكرارات والنسب المئوية. } \\
& \text { المتوسطات الموزونة. } \\
& \text { ه الانحراف المعياري. } \\
& \text { معامل ارتباط بيرسون. } \\
& \text { معامل ثبات ألفا كرونباخ. } \\
& \text { • اختبار T-test. }
\end{aligned}
$$

\begin{tabular}{|c|c|c|}
\hline القيمة الوزنية & الارجة & درجة الموافقة (القيمة الأسمية) \\
\hline من ا إلى 1,Vo & درجة & غير موافق بثدة \\
\hline أكبر من Y, l, إلى r,o r & درجتان & غير موافق \\
\hline 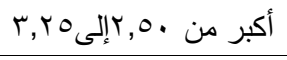 & ثلاث درجات & موافق \\
\hline أكبر من Or,r, إلى ع & أربع درجات & موافق بشدة \\
\hline
\end{tabular}

اختبار كروسكال واليس Kruskal - Wallis.

جدول (ه): يوضح القيمة الوزنية والاسمية لارجة الموافقة على عبارات الاستبيان

عرض النتائج ومناقشتها:

السؤال الأول: ما أهم أسباب سوء استخدام وسائل التواصل الاجتماعي (تويتر Twitter) ؟ 
للإجابة عن هذا السؤال قام الباحث بتقسيم المحور الأول للاستبيان إلى سبعة أسباب تمثل أسباب سوء استخدام وسائل التواصل الاجتماعي (تويتر Twitter أنموذجاً). وقد تم استخدام النسب المئوية والتكرارات والمتوسطات الحسابية الموزونة والانحراف المعياري لقياس درجة توفر هذه الأسباب، حيث جاء المتوسط الحسابي للأسباب السبعة (r, r, أي أنها تتوفر بدرجة عالية من وجهة نظر الطلاب، ويوضح جدول رقم (†) ترتيب تلك الأسباب كما يلي:

جدول (†): المتوسط الحسابي والانحراف المعياري لأسباب سوء استخدام وسائل التواصل الاجتماعي (تويتر Twitter)

\begin{tabular}{|c|c|c|c|c|c|}
\hline الارجة & الترتيب & الانحراف المعياري & المتوسط الحسابي & السبب & p \\
\hline موافق بشدة & 1 & . & $r, r q$ & ضعف التوثيق & 1 \\
\hline موافق & v & $\cdot, \wedge$. & r.Vq & الكنب والإشاعات & $r$ \\
\hline موافق & 7 &., $0 \leqslant$ & $r, .1$ & التشبث بالرأي & $r$ \\
\hline موافق & 0 & . or & $r, \cdot \varepsilon$ & إثارة المشكلات & $\varepsilon$ \\
\hline موافق & r & $\cdot, 0$ & $r, I V$ & المخاطرة في الطرح & 0 \\
\hline موافق & r & ., or & $r, 1 \Lambda$ & عدم القدرة على التحليل & 9 \\
\hline موافق & $\varepsilon$ &., 00 & $r, \cdot \wedge$ & الخروج عن المألوف & $\mathrm{v}$ \\
\hline
\end{tabular}

ويوضح الجدول السابق أن ضعف التوثيق احتل المرتبة الأولى بمتوسط وץ,r ، يليه (علدم القدرة على التحليل) بمتوسط

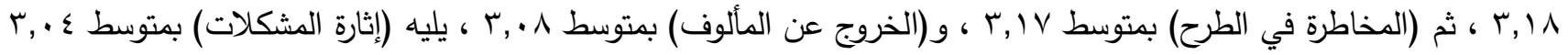

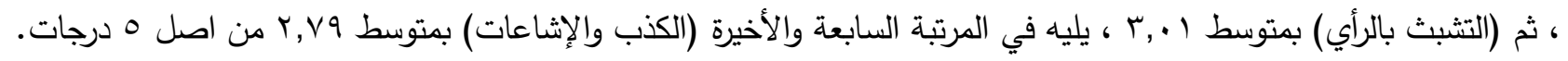
التحقق من فرضيات الدراسة الفرض الصفري الأول: لا توجد فروق ذات دلالة إحصائية عند مستوى معنوية (0... •) في وجهة نظر الطلاب تجاه أسباب سوء

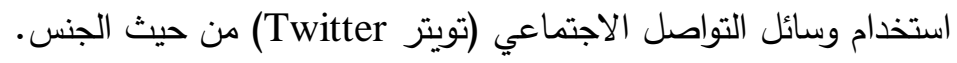
ولفص هذا الفرض تم إجراء اختبار (ت) للعينات المستقلة حيث يحتوي كل متغير على مجموعتين فقط فيندرج تحت متغير الجنس (ذكر - أنثى) ويبين جدول رقم (V) نتائج الاختبار .

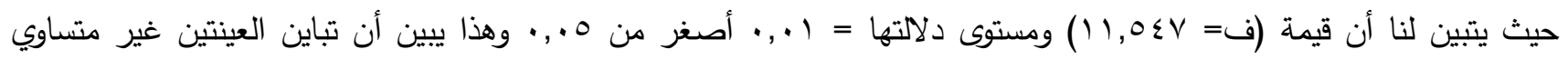

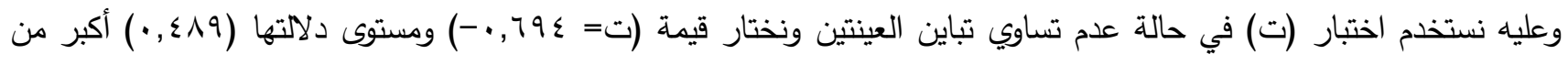

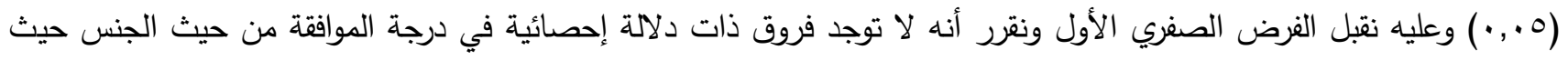

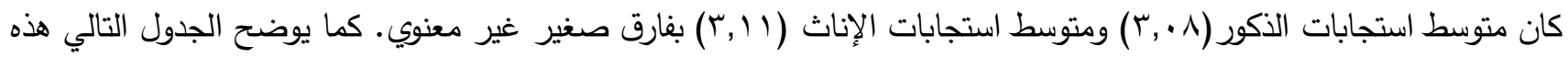
النتائج: جدول (V): نتائج اختبار (ت) لأسباب سوء استخدام وسائل التواصل الاجتماعي (تويتر Twitter) من حيث الجنس

\begin{tabular}{|c|c|c|c|c|c|}
\hline مستوى الالالة & درجات الحرية & ت & الانحراف & الحستوسطي & \\
\hline \multirow{2}{*}{$\cdot, \sum \wedge १$} & \multirow{2}{*}{101} & \multirow{2}{*}{.,$- 79 \leq$} & $\cdot, Y_{4}$ & $r, \cdot \Lambda$ & ذكر \\
\hline & & & $\cdot, \varepsilon r$ & $r, 11$ & أنثى \\
\hline
\end{tabular}


الفرض الصفري الثاني: لا توجد فروق ذات دلالة إحصائية عند مستوى معنوية (ه., •) في وجهة نظر الطلاب تجاه أسباب سوء

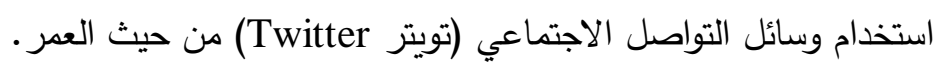

ولفحص هذا السؤال تم حساب الوسط الحسابي والانحراف المعياري وتحليل كروسكال واليس للاستبيان الذي هو قيد الديد الدراسة

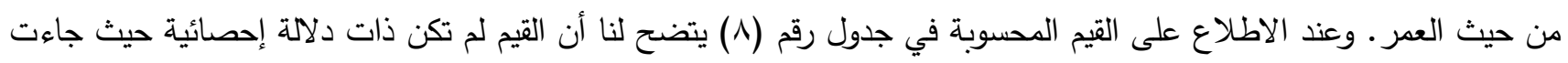
قيمة الدلالة (r^ ا, •) أكبر من (0., •) مما يثير إلى قبول الفرض الصفري الثاني ونقرر عدم وجود فروق ذات دلالة إحصائية في درجة الموافقة على أسباب سوء استخدام وسائل التواصل الاجتماعي (تويتر Twitter) من حيث العمر في عينة الدراسة. كما يوضح الجدول التالي هذه النتائج:

جدول (^): نتائج تحليل كروسكال واليس Kruskal - Wallis من حيث العمر

\begin{tabular}{|c|c|c|c|c|c|c|c|}
\hline الدلالة & مستوى & الحربة & الاختبار & متوسطات & الحسوسطات & العدد & العمر \\
\hline \multirow{3}{*}{ غال } & \multirow{3}{*}{ rגו,. } & \multirow{3}{*}{$r$} & \multirow{3}{*}{$r, r q \uparrow$} & $\wedge \leqslant, 09$ & r & 117 & 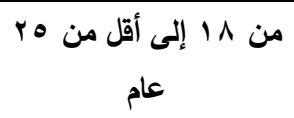 \\
\hline & & & & $v \cdot, 9 \Lambda$ & $r, . \top$ & r & 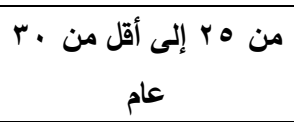 \\
\hline & & & & $70, \wedge 7$ & r, qV & 11 & أكبر من · ب عام \\
\hline
\end{tabular}

ويوضح الرسم البياني التالي هذه النتائج حيث تقارب قيم المتوسطات للفئات العمرية الثلاثة وانحصارها في درجة الموافقة حيث

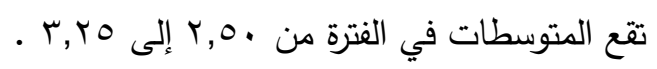

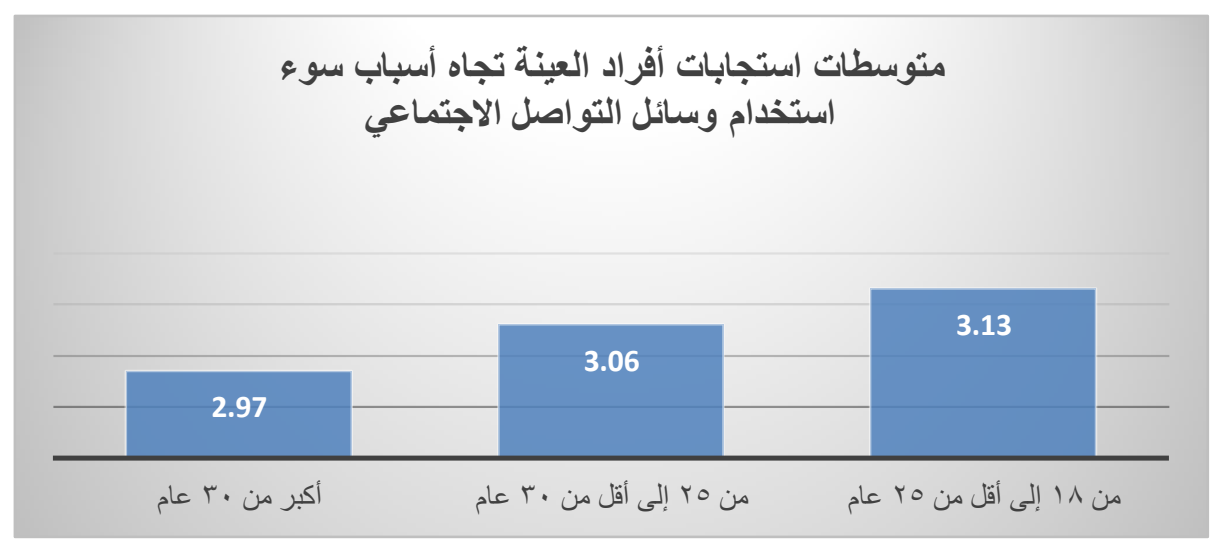

شكل (1): أسباب سوء استخدام وسائل التواصل الاجتماعي (تويتر Twitter)

السؤال الثاني: ما هي المعوقات التي تحول بين الاستخدام الأمثل لوسائل التواصل الاجتماعي (تويتر Twitter إنموذجًا)؟ وللإجابة عن هذا السؤال قام الباحث بتقسيم المحور الثاني للاستبيان إلى معوقين رئيسيين وهما: المعوقات التنظيمية،

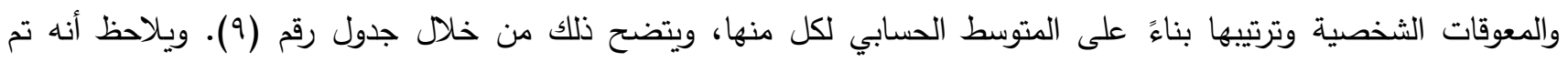
استخدام النسب المئوية والتكرارات والمتوسطات الحسابية الموزونة والانحراف المعياري للعبارات التي تقيس كل معوق على على حدة: القسم الأول: المعوقات التتظيمية للاستخدام الأمثل لوسيلة التواصل الاجتماعي (تويتر وwitter) 
جذول (9): المعوقات التظظيمة للاستخدام الأمثل لوسائل التواصل الاجتماعي (تويتر إنموذجًا)

\begin{tabular}{|c|c|c|c|c|c|c|c|c|c|}
\hline \multirow[b]{2}{*}{ 霄: } & \multirow[b]{2}{*}{ المتوسط } & \multirow[b]{2}{*}{ 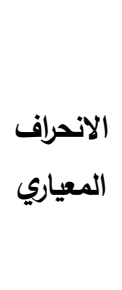 } & \multicolumn{4}{|c|}{ درجة الموافقة } & \multirow[b]{2}{*}{$\begin{array}{l}s \\
\%\end{array}$} & \multirow[b]{2}{*}{ التواصل الاجتماعي (تويتر Twitter التنظيمية للاستخام الأمثل لوسائل } & \multirow[b]{2}{*}{ ? } \\
\hline & & & بثدة غوافق & غوافق & موافق & بثدة & & & \\
\hline 9 & r, १V & $\cdot, \wedge \vee$ & $\stackrel{0}{r, 1}$ & $\begin{array}{l}\varepsilon \wedge \\
r\end{array}$ & $\begin{array}{c}0 \leqslant \\
r r, \Lambda\end{array}$ & $\begin{array}{l}\text { or } \\
r r, 1\end{array}$ & $\begin{array}{l}5 \\
\%\end{array}$ & عدم نشر اللوائح والأنظمة الخاصة بالأمن & 1 \\
\hline v & $r, . \leq$ & $\cdot, 90$ & $\begin{array}{l}11 \\
7,9 \\
\end{array}$ & $\begin{array}{l}r_{0} \\
r_{1}, q\end{array}$ & $\begin{array}{c}0 . \\
r 1, r\end{array}$ & 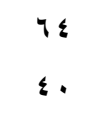 & $\begin{array}{l}5 \\
\%\end{array}$ & تعتبر التكاليف المادية عقبة أمام الأفكار & r \\
\hline$r$ & r,or & $\cdot, \mathrm{V} \leqslant$ & $\begin{array}{l}r \\
1, r\end{array}$ & 11 & $\begin{array}{c}r \leq \\
r 1, r\end{array}$ & $\begin{array}{l}1.9 \\
78,4\end{array}$ & $\begin{array}{l}5 \\
\%\end{array}$ & عدم وجود صلاحيات الرقابة للجهات المعنية & r \\
\hline$\wedge$ & $r, \cdot r$ & $\cdot, 97$ & 14 & $\begin{array}{rr}r \\
r\end{array}$ & $\begin{array}{l}\Delta r \\
r r, O\end{array}$ & $\begin{array}{c}i r \\
r q, \varepsilon\end{array}$ & $\begin{array}{l}5 \\
\%\end{array}$ & المزايا الممنوحة للمراقب لا تتناسب مع ما يبذله & $\varepsilon$ \\
\hline 7 & $r, r$. & $\cdot, \wedge \wedge$ & ^ & $\begin{array}{l}r 1 \\
\mid r, 1\end{array}$ & $\begin{array}{c}\leqslant \uparrow \\
r \wedge, \wedge\end{array}$ & $\begin{array}{l}\text { no } \\
\text { or, } 1\end{array}$ & $\begin{array}{l}5 \\
\%\end{array}$ & كثرة الحسابات وتشعبها ما بين حقيقية ووهمية & 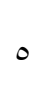 \\
\hline$\varepsilon$ & $r, O$. & •,Ar & $\begin{array}{l}1 \\
0\end{array}$ & $\begin{array}{c}9 \\
0,7\end{array}$ & $\begin{array}{l}r \wedge \\
r \mu, \Lambda\end{array}$ & $\begin{array}{l}1.0 \\
10,7\end{array}$ & $\begin{array}{l}5 \\
\%\end{array}$ & مقاومة الجمهور نظم الرقابة وعدم رغبتها في & 7 \\
\hline 1 & $r, \boldsymbol{T}$ & •, TV & $\varepsilon$ & $\begin{array}{c}0 \\
r, 1\end{array}$ & $\begin{array}{c}\leqslant \\
r 0, r\end{array}$ & $\begin{array}{ll}11 . \\
71,1\end{array}$ & $\begin{array}{l}5 \\
\%\end{array}$ & قلة الاهتمام بتطوير برامج أنظمة الأمن & V \\
\hline 0 & $r, \leqslant v$ & $\cdot, 79$ & $\begin{array}{c}1 \\
\cdot, 7\end{array}$ & $\begin{array}{l}19 \\
1 .\end{array}$ & $\begin{array}{l}0 . \\
r, r\end{array}$ & $\begin{array}{ll}q 4 \\
0 \wedge, 1\end{array}$ & $\begin{array}{l}5 \\
\%\end{array}$ & عدم الأخذ بعين الاعتبار وسائل التواصل & $\wedge$ \\
\hline r & $r, \infty 0$ & $\cdot, \mathrm{VY}$ & $\varepsilon$ & $\begin{array}{c}9 \\
0,7\end{array}$ & 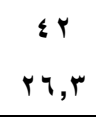 & 1.0 & $\begin{array}{l}5 \\
\%\end{array}$ & عدم الاستفادة من التجارب العالمية الرائدة في & 9 \\
\hline بشدة موافق & $r, r r$ & $\cdot, r q$ & & & & & & المتوسط الموزون لمحور المع & \\
\hline
\end{tabular}

يتضح من الجدول السابق أن المرتبة الأولى للمعوقات التنظيمية كانت (قلة الاهتمام بتطوير برامج أنظمة الأمن المعلوماتي) بمتوسط (7, ب من أصل (ع) ، يليه (عدم الاستفادة من التجارب العالمية الرائدة في مكافحة الجريمة الإلكترونية) في المرتبة الثانية

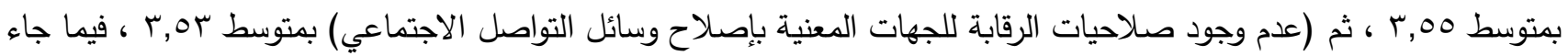

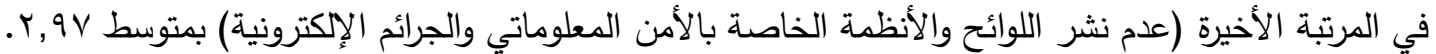
كما يلاحظ أن درجة استجابة الطلاب على جميع المعوقات هي (الموافقة بشدة ) أو (الموافقة) حيث كانت المتوسطات

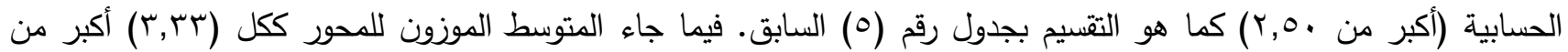
ه,r,r. أي أن أفراد عينة الدراسة يتفقون بشدة على المعوقات التنظيمية التسعة للاستخدام الأمثل لوسيلة التواصل الاجتماعي (تويتر .(Twitter

القسم الثاني: المعوقات الشخصية للاستخدام الأمثل لوسيلة التواصل الاجتماعي (تويتر Twitter) يوضح جدول رقم (• () الانحراف المعياري والمتوسط الموزون للمعوقات الثخصية، ورتبها الباحث تتازليًا حسب المتوسط الحسابي. 
جدول (· (1): المعوقات الثخصية للاستخدام الأمثل لوسائل التواصل الاجتماعي (تويتر إنموذجًا)

\begin{tabular}{|c|c|c|c|c|c|c|c|c|c|}
\hline \multirow[b]{2}{*}{ 雮: } & \multirow[b]{2}{*}{ الم الموزون } & \multirow[b]{2}{*}{ المعياري } & \multicolumn{4}{|c|}{ درجة الموافقة } & \multirow[b]{2}{*}{ \% } & \multirow[b]{2}{*}{ التواصل الاجتماعي (تويتر الثوقات الثختذام الأمثل لوسائل } & \multirow[b]{2}{*}{ م } \\
\hline & & & بثرة & 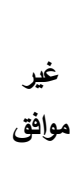 & موافق & بثدة موافق & & & \\
\hline 1 & $r, \leqslant 9$ & $\cdot, \mathrm{Vr}$ & $\stackrel{\varphi}{i, r}$ & $\begin{array}{l}10 \\
9,8\end{array}$ & $\begin{array}{l}\vdots \uparrow \\
Y \wedge, \wedge\end{array}$ & $\stackrel{q \vee}{i, 4}$ & \% & نقص الخبرة للمشاركة في وسائل التواصل & 1 \\
\hline$\varepsilon$ & r,or & $\cdot, \mathrm{V} r$ & $\begin{array}{l}\varepsilon \\
r, 0\end{array}$ & $\begin{array}{l}11 \\
1,9\end{array}$ & $\begin{array}{l}\varepsilon 1 \\
r 0, r\end{array}$ & $\begin{array}{l}1.8 \\
10\end{array}$ & \% & التردد في اقتراح أفكار جديدة عبر وسائل التواصل & r \\
\hline v & 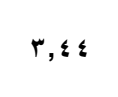 & $\cdot, \mathrm{V} \leqslant$ & $\stackrel{r}{1,9}$ & $\begin{array}{l}10 \\
9,8\end{array}$ & $\begin{array}{c}01 \\
r 1,9\end{array}$ & $\begin{array}{l}91 \\
.04\end{array}$ & $\begin{array}{l}5 \\
\%\end{array}$ & الخوف من الاخول في دوائر الصراع عبر وسائل & $r$ \\
\hline$\bullet$ & $r, 0$. & $\cdot, \mathrm{Vr}$ & $\stackrel{r}{1,9}$ & $\begin{array}{ll}i r \\
r, 0\end{array}$ & $\begin{array}{l}\varepsilon \vee V \\
r q, \varepsilon\end{array}$ & $\begin{array}{ll}9 \Lambda \\
71, r\end{array}$ & $\begin{array}{l}5 \\
\%\end{array}$ & فقد الجرأة على نقد الممارسات الخاطئة في وسائل & $\varepsilon$ \\
\hline$r$ & $r, r_{0}$ & $\cdot, 01$ & $\frac{1}{1}$ & $\begin{array}{c}\uparrow \\
r, \wedge\end{array}$ & $\begin{array}{c}\varepsilon \\
r_{0,4}\end{array}$ & $\begin{array}{ll}11 r \\
v .\end{array}$ & $\begin{array}{l}5 \\
\%\end{array}$ & اعتقاد أن من الصعب تغيير واقع وسائل التواصل & - \\
\hline$\wedge$ & $r, r r$ & -, $\vee 9$ & $\stackrel{r}{i, r}$ & $\begin{array}{ll}M \\
14, r\end{array}$ & $\begin{array}{l}0 . \\
r i, r\end{array}$ & $\begin{array}{ll}\wedge r \\
\Delta 1, r\end{array}$ & $\begin{array}{l}4 \\
\%\end{array}$ & انخفاض مستوى الرضا النفسي عن وسائل التواصل & 1 \\
\hline 9 & $r, r r$ & • & $\begin{array}{l}V \\
\varepsilon, \xi\end{array}$ & $\begin{array}{l}\text { iv } \\
1 ., 4\end{array}$ & $\begin{array}{l}0 \leq \\
r r, \Lambda\end{array}$ & $\begin{array}{cl}\Delta r \\
\Delta 1, r\end{array}$ & $\begin{array}{l}5 \\
\%\end{array}$ & اقتصار النظرة للمشاكل المطروحة في وسائل & $v$ \\
\hline 1 & $r, \nabla \mu$ & $\cdot, 01$ & $\stackrel{r}{i, r}$ & $\stackrel{\bullet}{r, 1}$ & $\begin{array}{l}r v \\
17,9\end{array}$ & $\begin{array}{l}1 \mathrm{rq} \\
\mathrm{VA, \Lambda}\end{array}$ & $\begin{array}{l}5 \\
\%\end{array}$ & التردد في الاستفسار عما يرد من معلومات في & $\wedge$ \\
\hline$r$ & $r, \uparrow$ & $\cdot, \mathrm{V} \varepsilon$ & 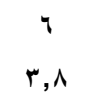 & $\begin{array}{c}r \\
r, \wedge\end{array}$ & $\begin{array}{ll}\text { rer } \\
r .\end{array}$ & $\begin{array}{l}117 \\
V Y, 0\end{array}$ & s & تفضيل الاستقرال وعدم الميل إلى التغيير. & 9 \\
\hline مبثدة - موافق & $r, 01$ & r & & & & & & المتوسط الموزون & \\
\hline
\end{tabular}

يتضح من الجدول السابق أن المرتبة الأولى للمعوقات الشخصية كانت (التردد في الاستفسار عما يرد من معلومات في وسائل

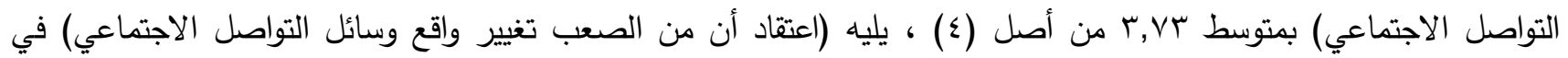

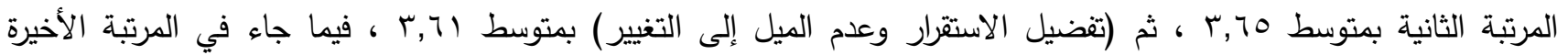

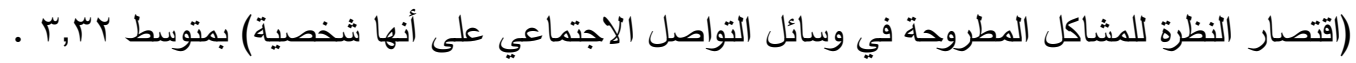
كما يلاحظ أن درجة استجابة الطلاب على جميع المعوقات هي (الموافقة بثدة) أو (الموافقة) حيث كانت المتوسطات الحسابية

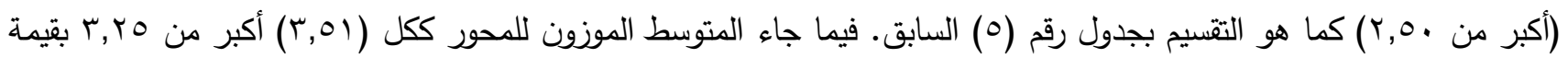
انحراف معياري صغيرة (דب, •·) مما يدل على تجانس الاستجابات وعدم تشتتها حول المتوسط. أي أن أفراد عينة الدراسة يتفقون

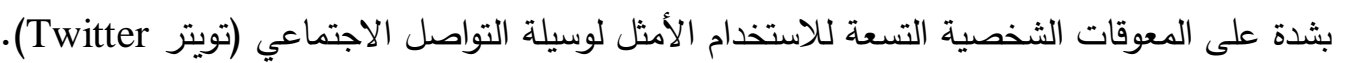
السؤال الثالث: ما هي أهم مقترحات وتوصيات المساهمة في الحد من سوء استخدام وسيلة التواصل الاجتماعي (تويتر ؟(Twitter

وللإجابة عن هذا السؤال قام الباحث بحساب المقترحات التي يراها أفراد الدراسة، ويوضح جدول رقم (1) الانحراف المعياري والمتوسط الموزون للمقترحات والتوصيات المساهمة في الحد من سوء استخدام وسيلة التواصل الاجتماعي (تويتر Twitter). 
جدول (11): الانحراف المعياري والمتوسط الموزون لمقترحات وتوصيات المساهمة في الحد من سوء استخدام وسيلة التواصل الاجتماعي (Twitter تويتر)

\begin{tabular}{|c|c|c|c|c|c|c|c|c|c|}
\hline \multirow[b]{2}{*}{ 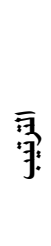 } & \multirow[b]{2}{*}{ المتونط } & \multirow[b]{2}{*}{ 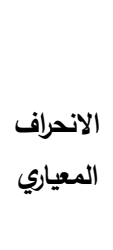 } & \multicolumn{4}{|c|}{ درجة الموافقة } & \multirow[b]{2}{*}{$\begin{array}{l}5 \\
\%\end{array}$} & \multirow[b]{2}{*}{$\begin{array}{c}\text { المقترحات والتوصيات المساهمة في الحد من سواء وسيلة التواصل الاجتماعي (تويتر } \\
\text { (Twitter }\end{array}$} & \multirow[b]{2}{*}{ p } \\
\hline & & & غير موافق & غير موافق & موافق & 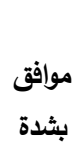 & & & \\
\hline$r$ & $r, 0 q$ & $\cdot, \mathrm{V}$. & $\begin{array}{l}r \\
1,9\end{array}$ & $\begin{array}{l}11 \\
7,9\end{array}$ & $\begin{array}{c}r \varepsilon \\
r 1, r\end{array}$ & $\begin{array}{l}11 r \\
v .\end{array}$ & $\begin{array}{l}\text { 5 } \\
\%\end{array}$ & مجال التربية والتعليم وجميع المؤسسات المعلوماتئ الإدارية من الإكترونية في & 1 \\
\hline V & $r, \varepsilon \wedge$ & $\cdot, V r$ & $\begin{array}{l}1 \\
7\end{array}$ & $\begin{array}{l}11 \\
11, r\end{array}$ & $\{\varepsilon$ & $\stackrel{\wedge \vee}{\top \cdot, \uparrow}$ & $\begin{array}{l}\text { 5 } \\
\%\end{array}$ & توفير الميزانيات المالية الكافية لإنثاء نظام رقابي & r \\
\hline 1 & $r, 7 \wedge$ & •, TV & 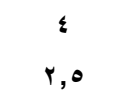 & $\begin{array}{c}1 \\
r, \Lambda\end{array}$ & $\begin{array}{l}r V \\
17,9\end{array}$ & $\begin{array}{l}\text { Irr } \\
V Y, q\end{array}$ & $\begin{array}{l}5 \\
\%\end{array}$ & كثف المعلومات لئفات بأرقام السجل المدني أو الهويات دون & $r$ \\
\hline 0 & $r, 00$ & $\cdot, V \leq r$ & 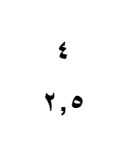 & $\begin{array}{ll}\text { Ir } \\
V, 0\end{array}$ & $\underset{r r, 0}{r q}$ & $1 \cdot 1$ & $\begin{array}{l}\text { 5 } \\
\%\end{array}$ & تكثيف الدورات الاينية لنبذ التيارات الفكرية المنحرفة & $\varepsilon$ \\
\hline 9 & $r, \varepsilon \leq$ & $\cdot, \wedge r$ & $\begin{array}{c}\bullet \\
r, 1\end{array}$ & $\begin{array}{l}19 \\
11,9\end{array}$ & $r_{r}^{r}$ & $\begin{array}{ll}1+. \\
r r, 0\end{array}$ & $\begin{array}{l}5 \\
\%\end{array}$ & 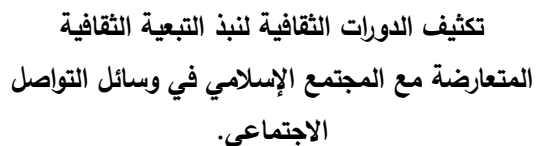 & 0 \\
\hline 1. & $r, r r$ & ד & $\begin{array}{c}r \\
r, \Lambda\end{array}$ & $\begin{array}{l}r T \\
1 \leqslant, \varepsilon\end{array}$ & $\begin{array}{c}\varepsilon \\
r v, 0\end{array}$ & $\begin{array}{c}A \vee \\
0 \leqslant, \varepsilon\end{array}$ & $\begin{array}{l}\text { 5 } \\
\%\end{array}$ & 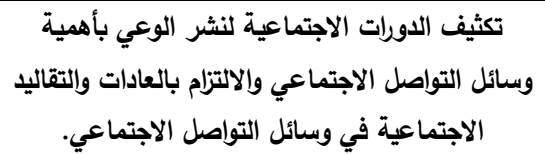 & 7 \\
\hline$\varepsilon$ & $r, 04$ & $\cdot, \mathrm{VV}$ & ^ & $\begin{array}{c}\varepsilon \\
r, 0\end{array}$ & $\begin{array}{c}r q \\
r \leq, \varepsilon\end{array}$ & $\begin{array}{l}1.9 \\
11,1\end{array}$ & $\begin{array}{l}5 \\
\%\end{array}$ & 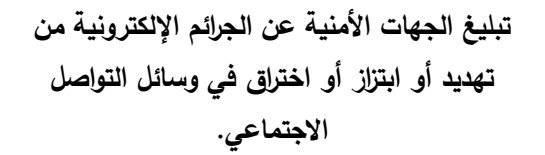 & $v$ \\
\hline 7 & $r, \circ r$ & $\cdot, \wedge$. & $\begin{array}{c}\bullet \\
r, 1\end{array}$ & 17 & $\stackrel{r \cdot}{i \wedge, \Lambda}$ & $\begin{array}{l}1.9 \\
11,1\end{array}$ & $\begin{array}{l}\text { 5 } \\
\%\end{array}$ & إنثاء شبكة من لجان التوعية الإكترونية في كافة & $\wedge$ \\
\hline$\wedge$ & $r, \leqslant \wedge$ & $\cdot, v_{0}$ & $\begin{array}{c}\varepsilon \\
r, \rho\end{array}$ & $\Lambda, 1$ & $\begin{array}{l}\leq \uparrow \\
r \wedge, \Lambda\end{array}$ & $\begin{array}{c}9 \vee \\
7 ., 7\end{array}$ & $\begin{array}{l}\text { ك } \\
\%\end{array}$ & 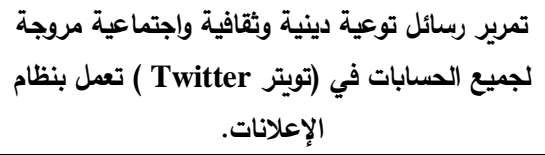 & 9 \\
\hline$r$ & $r, T \leqslant$ &., 09 & $\begin{array}{c}1 \\
\cdot, 7\end{array}$ & $\begin{array}{c}V \\
\varepsilon, \varepsilon\end{array}$ & $\begin{array}{c}\leqslant 1 \\
Y_{0, Y}\end{array}$ & $\begin{array}{l}111 \\
79,8\end{array}$ & $\begin{array}{l}\text { ك } \\
\%\end{array}$ & 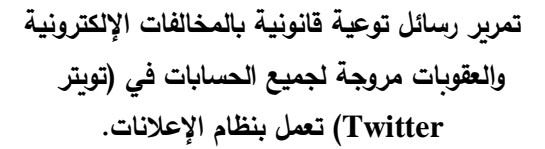 & 1. \\
\hline
\end{tabular}




\begin{tabular}{|c|c|c|c|c|c|c|c|c|c|}
\hline ir & $r, r_{1}$ & $\cdot, \wedge \vee$ & $\hat{\imath}$ & $i_{i \leqslant, \xi}^{r T}$ & $\stackrel{O V}{r 0, r}$ & $\begin{array}{l}V Y \\
\leq 0\end{array}$ & $\begin{array}{l}5 \\
\%\end{array}$ & تكريم المغرين الأكثر إيجابية وتأثير في وسائل & 11 \\
\hline 11 & $r, \Upsilon \wedge$ & $\cdot, \wedge$ & $\begin{array}{l}v \\
\varepsilon, \xi\end{array}$ & $\begin{array}{l}1 \leqslant \\
\wedge, \wedge\end{array}$ & $\begin{array}{l}r 1 \\
\vdots 1, r\end{array}$ & $\begin{array}{l}V \mu \\
\vdots 0, r\end{array}$ & $\begin{array}{l}5 \\
\%\end{array}$ & نشر أخبار جرائم الأمن المعلوماتي والعقوبات المترتبة & ir \\
\hline & $r, \leqslant r$ & $\cdot, r_{0}$ & \multicolumn{7}{|c|}{ المتوسط الموزون لمحور المقترحات والانحراف المعياري } \\
\hline
\end{tabular}

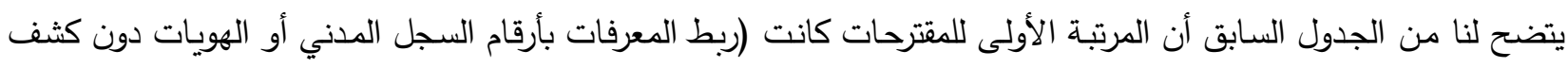

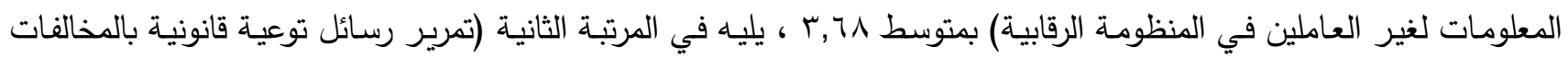

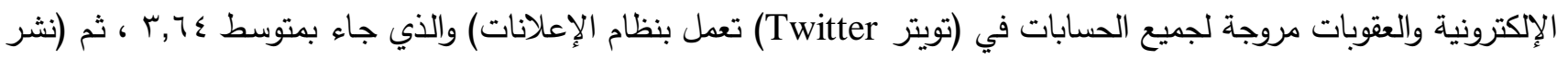

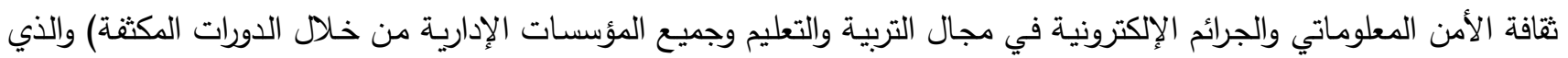

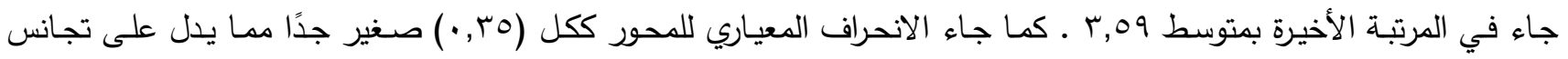

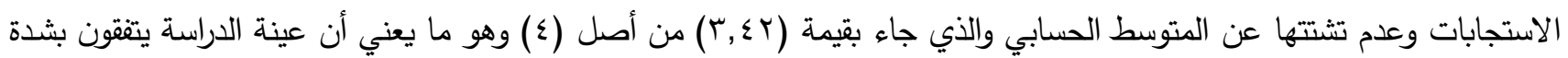
على هذه المقترحات.

\section{ملخص النتائج:}

أولاً: توصلت الدراسة الحالية إلى اتفاق سائد بين أفراد الدراسة من الذكور والإناث على الموافقة على أسباب سوء استخدام وسائل التواصل الاجتماعي مما يؤثر بدرجة عالية على الاستجابة والطلاب.

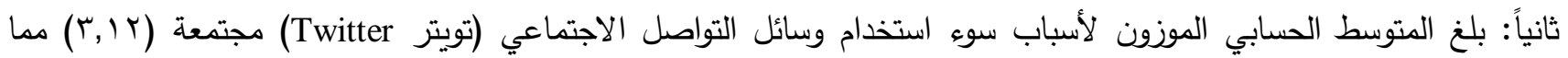

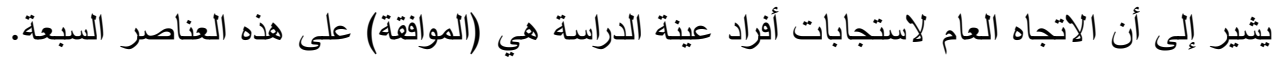

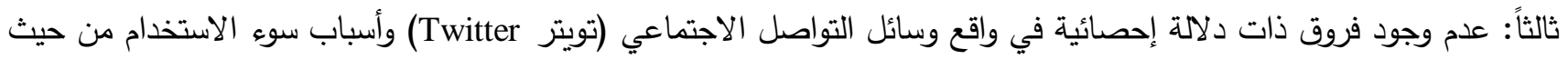
الجنس. رابعاً: عدم وجود فروق ذات دلالة إحصائية في واقع وسائل التواصل الاجتماعي (تويتر Twitter) وأسباب سوء الاستخدام من حيث عمر أفراد العينة. خامساً: توصلت الدراسة لمقترحات وتوصيات يمكنها أن تساهم في الحد من سوء استخدام وسيلة التواصل الاجتماعي (تويتر .(Twitter

\section{التوصيات:}

توصلت الدراسة لعدة توصيات ونتائج تعذر ربطها بأي دراسات سابقة لاقتصار الدراسات السابقة في هذا المجال على إثبات التأثير السلبي لوسائل التواصل الاجتماعي، في حين أن الدراسة الحالية أوجدت أسباب سوه استخدام وسائل التواصل الاجتماعي، لئل وعليه يمكن عرض عدد من التوصيات منها:

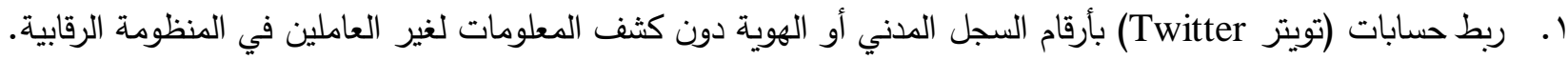
r. ب. ضرورة تفعيل (تويتر Twitter) عبر مكاتب التربية والتعليم والمدارس والمعاهد والجامعات وجميع المؤسسات الإدارية. r. العمل على نبذ أسباب سوء استخدام وسائل التواصل الاجتماعي (تويتر Twitter) بديًا من البيت والأسرة. ع. أهمية إنشاء لجان إلكترونية متخصصة دينية وعلمية ونفسية وقانونية للتوعية في كافة المجالات.

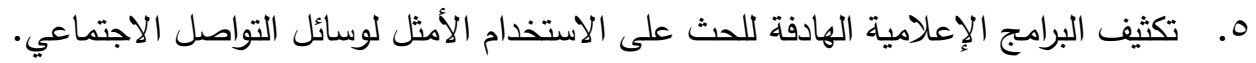
T. ضرورة تمكين المراقبة الإكترونية للجهات المعنية بالصلاحيات لمعاقبة المخالفين للأنظمة ومثيري الفتن. 


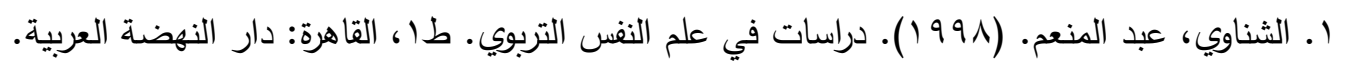

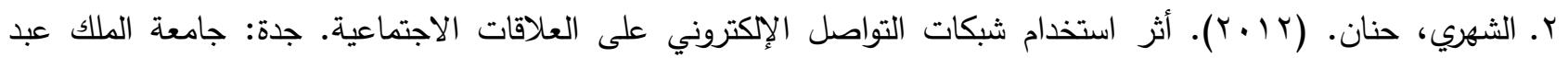

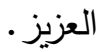

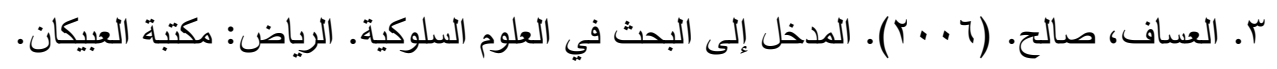

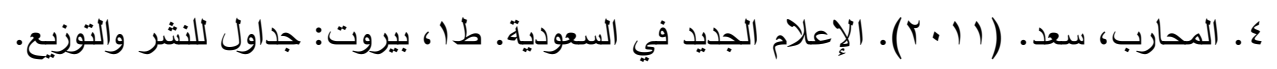

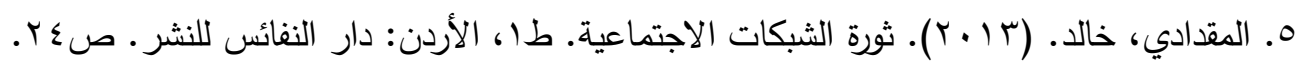

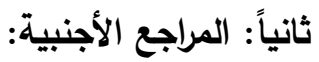

[1] P. Kabland, (1996). Pathway for Exceptional children school, home and cultures, st, paul, Minn. West publishing co.

[2] S. Lepore, (1994). Encyclopedia of Human Behavior, 4: 247-251.

[3] J. Nunnally \& I.Bernstein, (1994). Psychometric theory (3rd ed.). New York: McGraw-Hill. 


\title{
Reasons for Misuse of Social Media (Twitter model)
}

\author{
Majid Abdulfattah Mohammed Bokari \\ College of Education - Department of Psychology - Statistic and Research \\ M-BOUKHARI@ hotmail.com
}

\begin{abstract}
:
The study aimed to identify the reality of the bad employment of social media through Twitter as a modern model for the means of social communication. To achieve this, a random sample of (160) students was selected represent $40 \%$ from the selected research community.

In order to answer the questions of the study, a questionnaire was designed to identify the reasons for misuse of social media (Twitter model) and obstacles to optimal use, and suggestions to reduce the misuse of this means, and then used the researcher statistical treatments after analyzing the forms through the statistical program SPSS v.23, the most important results of the statistical analysis were: Identify the most important reasons for the misuse of social media (Twitter model). There were no statistically significant differences at a level $(0.05)$ in the students point of view towards reasons for misuse of social media (Twitter model) in terms of gender (male - female). There were no statistically significant differences at a level (0.05) in the students point of view towards reasons for misuse of social media (Twitter model) in terms of age. Identify the most important obstacles to the optimal recruitment of social media (Twitter model). Identify the most important proposals to contribute to reducing the misuse of social media (Twitter model).

The researcher came out with a number of recommendations including: Connect Twitter accounts with civil registration or identity numbers without disclosing information to non-employees in the regulatory system, and necessary to activate Twitter through educational offices, schools, institutes, universities and all administrative institutions, and the importance of establishing electronic committees specialized religious, legal, scientific, psychological for awareness in all fields, and the intensification of information programs aimed at promoting the optimal use of social media, and the need to enable electronic monitoring of the authorities concerned to punish violators of regulations and instigators.
\end{abstract}

Keywords: Social Media, Twitter, Reasons for Misuse of Social Media. 
الملاحق

بسم الله الرحمن الرحيم

وفقه الله

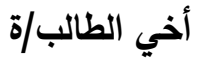

السلام عليكم ورحمة الله وبركاته .. وبعد:

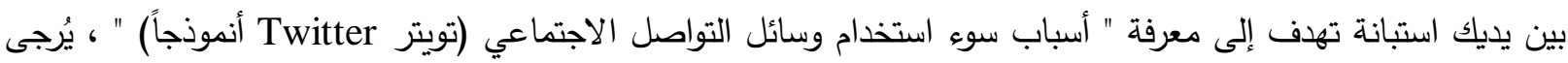

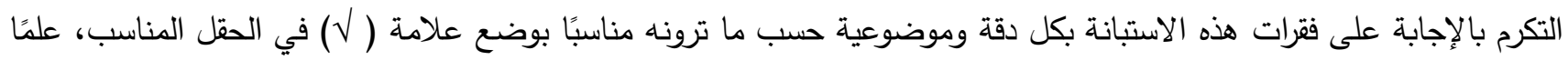
بأن هذه البيانات ستحاط بالسرية التامة ولن شُستخدم إلا لأغراض البحث العلمي فقط ، مع وافر الثكر والتقدير لتعاونكم.

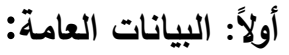

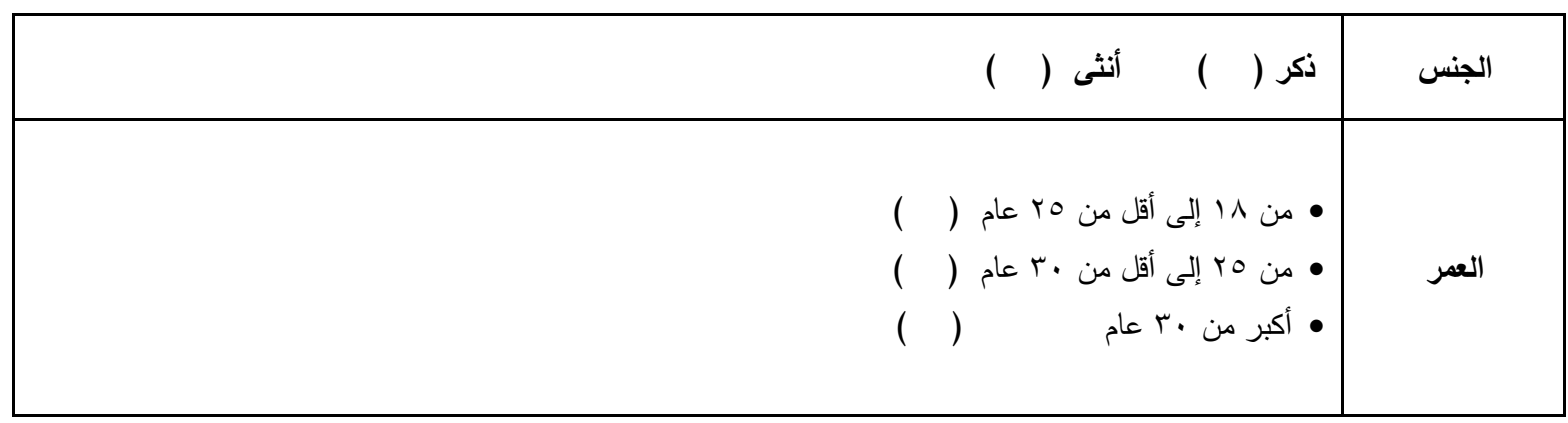

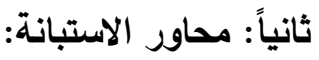

الدحور الأول: واقع التواصل الاجتماعي من خلال أسباب سوء استخام وسائل التواصل الاجتماعي (تويتر Twitter أنموذجًا):

\begin{tabular}{|c|c|c|c|c|c|c|}
\hline بثرافق & 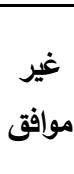 & موافق & بثدة - مقق & العبـــاة & الأسباب & رقم العبارة \\
\hline & & & & ينتقر بعض المغردين للأدلة الموثقة في الطرح عبر وسيلة التواصل & - & e \\
\hline & & & & ديليل أو توثيق. المغردين أن التغيير بناء على حرية الرأي لا يحتاج & 3 & r \\
\hline & & & & يعتمد بعض المغردين كلام المشاهير دليل موثوق. & “7. & $r$ \\
\hline & & & & يعتمد بعض المغردين الهاشتاق النشط المتداول دليل موثق . & $\frac{T^{3}}{\sqrt{3}}$ & $\varepsilon$ \\
\hline & & & & التئرر بعض المغردين الأخطاء بناء على أفكار الآخرين بإعادة & 迹 & o \\
\hline & & & & مبتكرة بعيدًا عن الأصالة والتوثيق ـ ملول جديدة للمشكلات الراهنة بأفكار & $E$ & 7 \\
\hline & & & & يستخذم بعض المغردين الكذب وترويج الإشاعات & 2 & $v$ \\
\hline & & & & تعمل على نشر الكنب وترويج إلإشاعات . معرفات وهية ولجان إلكترونية & 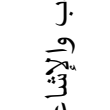 & $\wedge$ \\
\hline & & & & يستخدم بعض الدغردين التندي في لغة الحوار وإدارة النقاش لدفح & i. & q \\
\hline
\end{tabular}




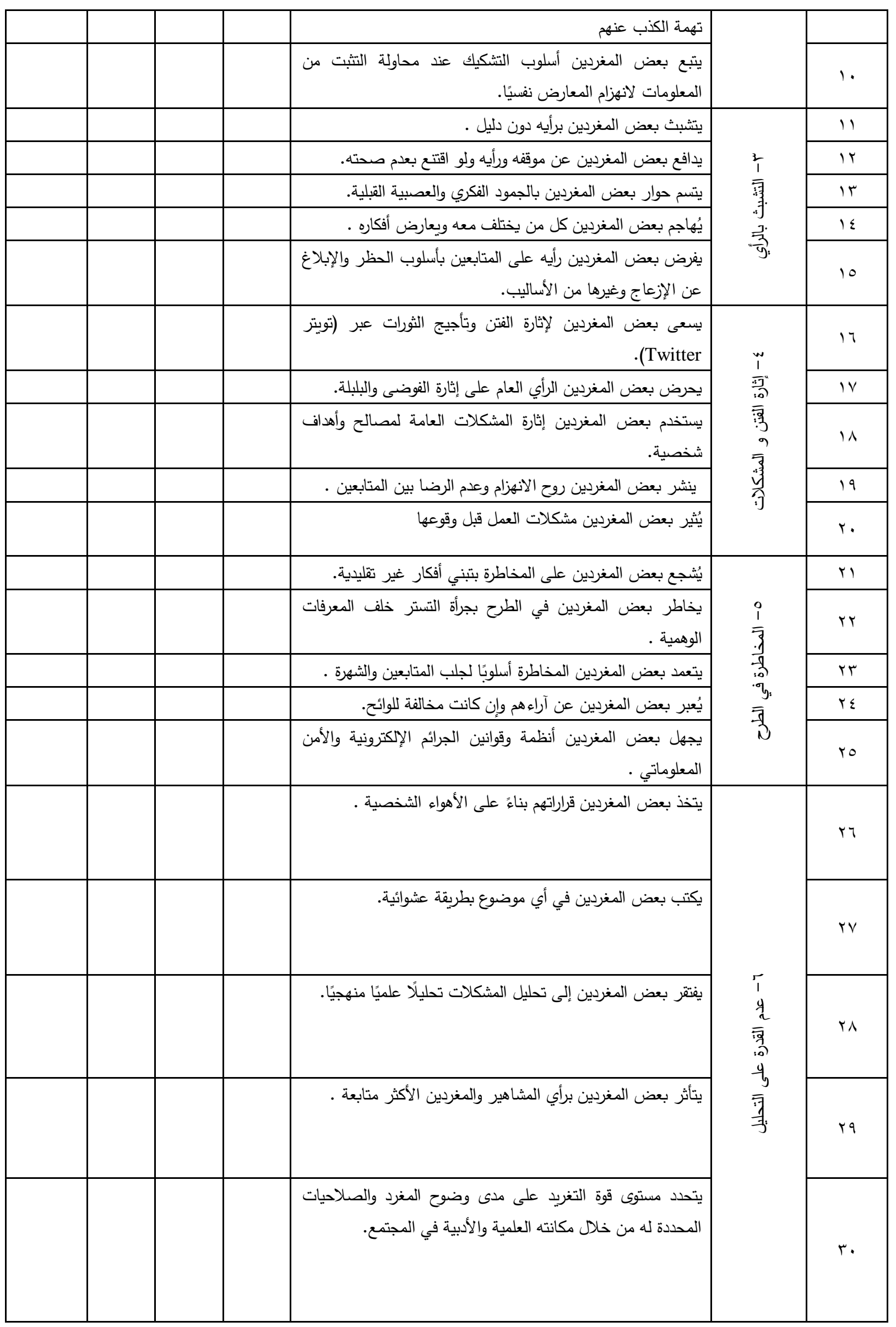




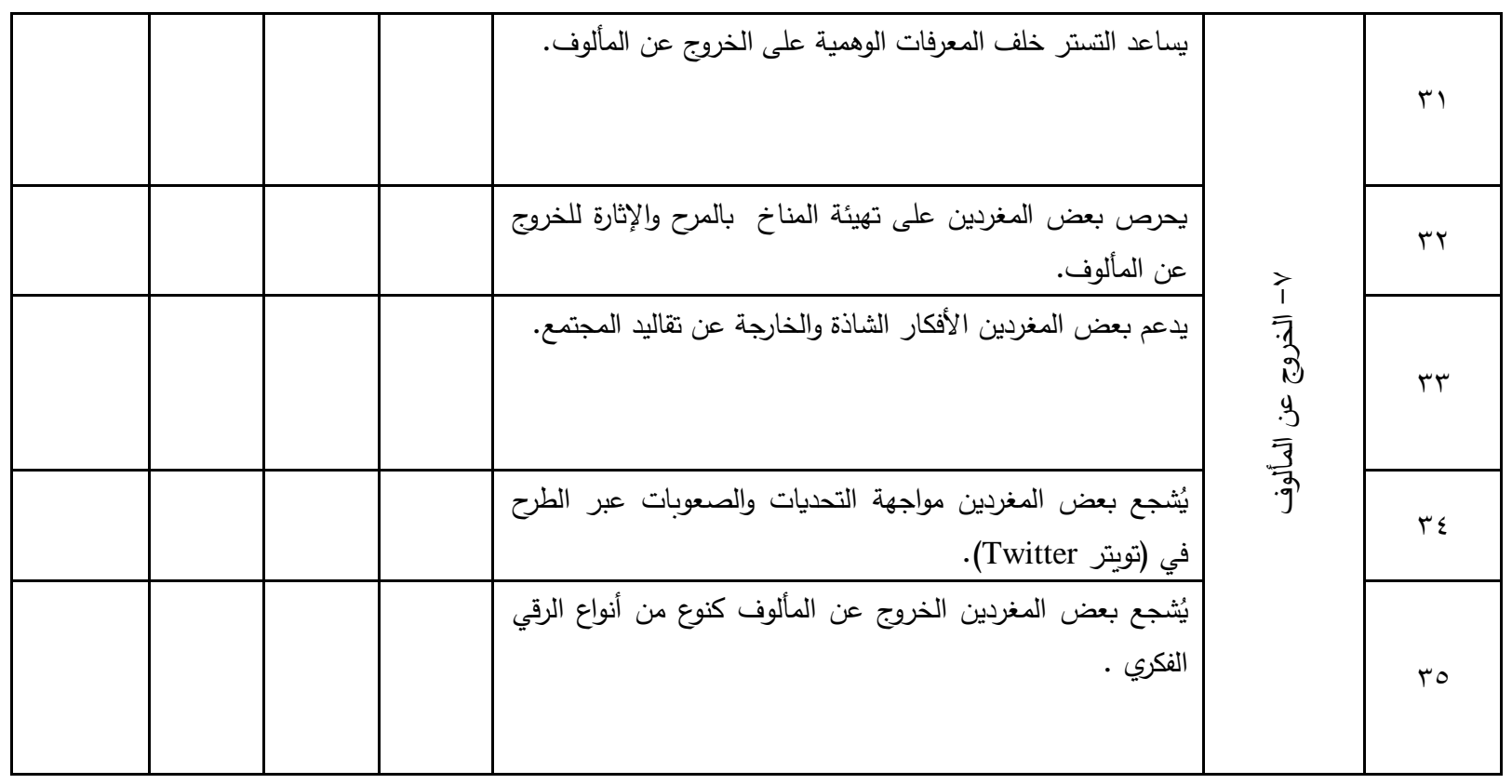

المحور الثاني: معوقات الاستخدام الأمثل لوسيلة التواصل الاجتماعي (تويترTwitter أنموذجًا):

\begin{tabular}{|c|c|c|c|c|c|c|}
\hline بثافق & 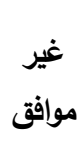 & 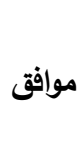 & موافق & العبـــــارة & المعوقات & 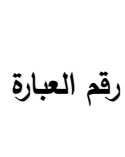 \\
\hline & & & & الإككترونية . عدم اللوائح والأنظمة الخاصة بالأمن المعلوماتي والجرائم & \multirow{9}{*}{ 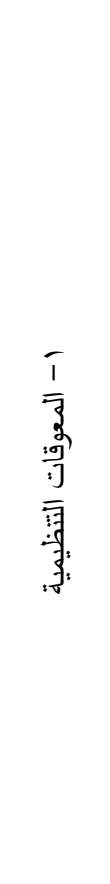 } & 1 \\
\hline & & & & تعتبر التكاليف المادية عقبة أمام الأفكار الإبداعية للرقابة دون & & $r$ \\
\hline & & & & عدم وجود صلاحيات الرقابة للجهات المعنية بإصلاح وسائل & & $r$ \\
\hline & & & & المزايا الممنوحة للمراقب لا تتناسب مع ما يبذله من جهد. & & $\varepsilon$ \\
\hline & & & & كثرة الحسابات وتشعبها ما بين حقيقية ووهمية عبر وسائل التواصل & & 0 \\
\hline & & & & مقاومة الجمهور نظم الرقابة وعدم رغبتها في التغيير. & & 7 \\
\hline & & & & قلة الاهتمام بتطوير برامج أنظمة الأمن المعلوماتي . & & $\mathrm{v}$ \\
\hline & & & & بالدراسة الأخذ بعين الاعتبار وسائل التواصل الاجتماعي الحديثة & & $\wedge$ \\
\hline & & & & الإكترونية الاستفادة من التجارب العالمية الرائدة في مكافحة الجريمة & & 9 \\
\hline & & & & نقص الخبرة للمشاركة في وسائل التواصل الاجتماعي عبر & 2 & 1. \\
\hline & & & & التردد في اقتراح أفكار جديدة عبر وسائل التواصل الاجتماعي. & \% & 11 \\
\hline & & & & الخوف من الاخول في دوائر الصراع عبر وسائل التواصل & $\overline{3}$ & Ir \\
\hline & & & & فقد الجرأة على نقد الممارسات الخاطئة في وسائل التواصل & : & 1T \\
\hline
\end{tabular}




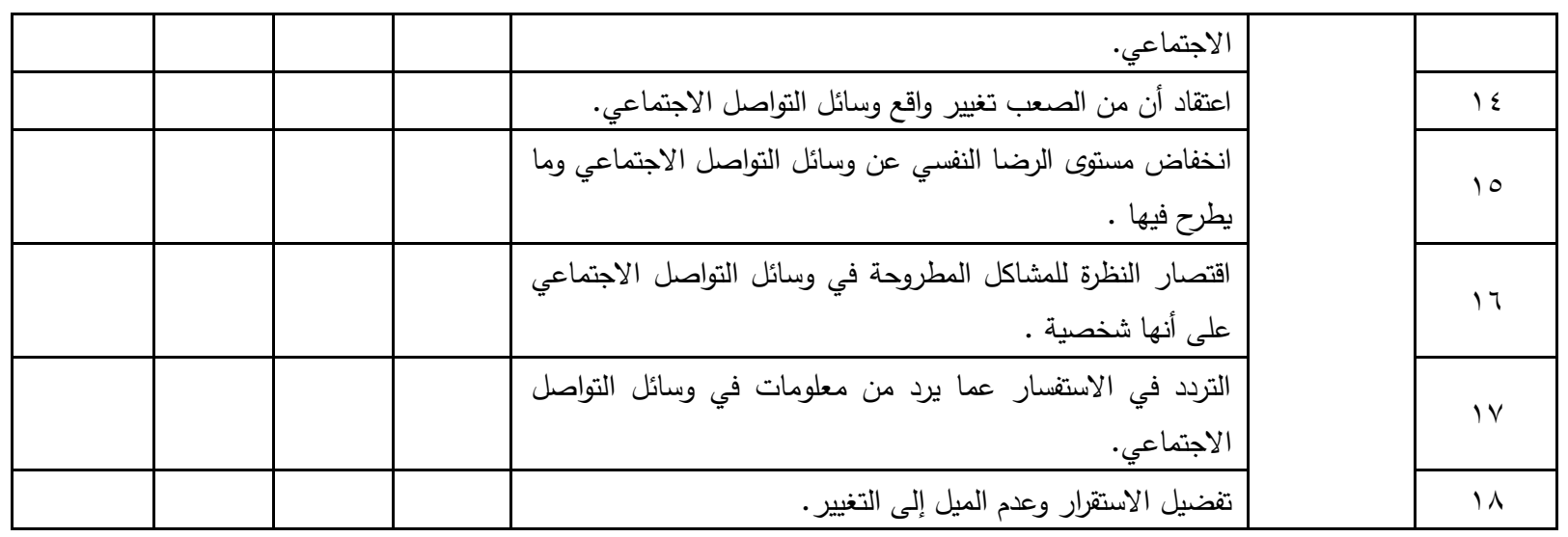

المحور الثالث: مقترحات وتوصيات للحد من أسباب سوء استخدام وسائل التواصل الاجتماعي (تويتر Twitter أنموذجًا):

\begin{tabular}{|c|c|c|c|c|c|}
\hline بثير & غوافق & 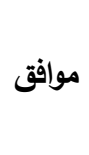 & بثدة - موافق & العبــــارة & 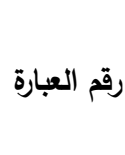 \\
\hline & & & & نشر ثقافة الأمن المعلوماتي والجرائم الإلكترونية في مجال التربية والتعليم وجميع & 1 \\
\hline & & & & التواصل الميزانيات المالية الكافية لإنشاء نظام رقابي إلكتروني يكفل الحريات في وسائل & $r$ \\
\hline & & & & ربط المعرفات بأرقام السجل المدني أو الهويات دون كثف المعلومات لغير العاملين في & $r$ \\
\hline & & & & 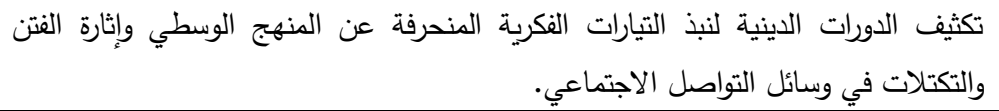 & $\varepsilon$ \\
\hline & & & & تكثيف الدورات الثقافية لنبذ التبعية الثقافية المتعارضة مع المجتمع الإسلامي في وسائل & 0 \\
\hline & & & & تكثيف الدورات الاجتماعية لنشر الوعي بأهمية وسائل التواصل الاجتماعي والالتزام & 1 \\
\hline & & & & تلتيغ الجهات الأمنية عن الجرائم الإلكترونية من تهديد أو ابتزاز أو اختراق في وسائل & V \\
\hline & & & & والعثلية. شبكة من لجان التوعية الإلكترونية في كافة المجالات والتخصصات الثرعية & $\wedge$ \\
\hline & & & & تعمل بنظام الإعلانات. تمينية وثقافية واجتماعية مروجة لجميع الحسابات في (تويتر Twitter) & 9 \\
\hline & & & & تمرير رسائل توعية قانونية بالمخالفات الإكترونية والعقوبات مروجة لجميع الحسابات في & 1. \\
\hline & & & & تكريم المغردين الأكثر إيجابية وتأثير في وسائل التواصل الاجتماعي. & 11 \\
\hline & & & & نشر أخبار جرائم الأمن المعلوماتي والعقوبات المترتبة عليها. & it \\
\hline
\end{tabular}

